\title{
Natural History, Outcomes and Antibiotic Treatment for Ventilator-Associated Tracheobronchitis in Critical Ill Patients
}

\author{
Yuxiu Lei1,2, Jana Hudcova ${ }^{3,4}$, Jawad Rashid3, Akmal Sarwar ${ }^{1,4}$, Wendy Gillespie ${ }^{5}$, \\ Carol Finn', Marie Goggin', Mohamed B. Omran ${ }^{3,4}$, Edward Boroda', Donald E. Craven ${ }^{2,4^{*}}$ \\ ${ }^{1}$ Pulmonary and Critical Care Medicine, Lahey Hospital and Medical Center, Burlington, MA, USA \\ ${ }^{2}$ Center for Infectious Diseases and Prevention, Lahey Clinic Hospital and Medical Center, Burlington, MA, USA \\ ${ }^{3}$ Surgical \& Medical Critical Care, Lahey Hospital and Medical Center, Burlington, MA, USA \\ ${ }^{4}$ Tufts University School of Medicine, Boston, MA, USA \\ ${ }^{5}$ Lab Medicine-Microbiology, Lahey Hospital and Medical Center, Burlington, MA, USA \\ ${ }^{6}$ Respiratory Care, Lahey Hospital and Medical Center, Burlington, MA, USA \\ Email: yuxiu.lei@lahey.org, jana.hudcova@lahey.org, jawadrashid@msn.com, akmal.Sarwar@lahey.org, \\ intermeedo@yahoo.com, Wendy.B.Gillespie@lahey.org, Carol.L.Finn@lahey.org, Marie.A.Goggin@lahey.org, \\ EDWARD.D.BORODA@lahey.org, "donald.e.craven@lahey.org
}

Received 16 January 2016; accepted 26 February 2016; published 29 February 2016

Copyright (C) 2016 by authors and Scientific Research Publishing Inc.

This work is licensed under the Creative Commons Attribution International License (CC BY). http://creativecommons.org/licenses/by/4.0/

(c) (i) Open Access

\section{Abstract}

We assessed incidence and outcomes of patients with ventilator-associated respiratory infections (VARI) due to tracheobronchitis (VAT) and pneumonia (VAP), including length of intensive care unit (ICU) stay and ventilator days. We also examined pathogens, rate of progression from VAT to VAP, and impact of antibiotic therapy for VAT. Data analysis included 234 patients, 100 patients $(43 \%)$ had at least moderate (+++) bacterial growth in their semi-quantitative endotracheal aspirate (SQ-ETA) cultures. VAT and VAP were each diagnosed in $34(15 \%)$ patients. Staphylococcus aureus was the most common pathogen isolated and had the highest rate of progression from VAT to VAP. Seven (21\%) of the 34 patients were diagnosed with VAT that later progressed to VAP in averaged 3 days. Patients diagnosed with VAT had significantly more ventilator days $(9$ vs $6, p<$ $0.001)$, ICU days $(17$ vs $11, p<0.001)$ and hospital days $(22$ vs $17, p<0.001)$. No significant difference was observed in the clinical outcomes of the 25 VAT patients with timely, appropriate antibiotics compared to the 9 VAT patients who did not receive timely appropriate antibiotics. VAT was a risk factor for increased ventilator days, longer length of ICU and hospital stay. The time window from VAT to VAP allowed physicians to identify the pathogens and sensitivity profile needed to treat VAT with appropriate antibiotics. Data from well-designed studies were needed to assess the impact of early, appropriate antibiotic therapy for VAT, the choice of antibiotics, as well "Corresponding author.

How to cite this paper: Lei, Y.X., Hudcova, J., Rashid, J., Sarwar, A., Gillespie, W., Finn, C., Goggin, M., Omran, M.B., Boroda, E. and Craven, D.E. (2016) Natural History, Outcomes and Antibiotic Treatment for Ventilator-Associated Tracheobronchitis in Critical III Patients. Modern Research in Inflammation, 5, 1-11. http://dx.doi.org/10.4236/mri.2016.51001 
as the duration and route of administration.

\title{
Keywords
}

\author{
Ventilator-Associated Tracheobronchitis (VAT) and Pneumonia (VAP), Bacterial Pathogens, \\ Semi-Quantitative Endotracheal Aspirate (SQ-ETA) Cultures, Antibiotic Therapy
}

\section{Introduction}

Intubated, mechanically ventilated patients are at increased risk for tracheal colonization with bacterial pathogens that over time may progress to ventilator-associated tracheobronchitis (VAT) and/or ventilator-associated pneumonia (VAP) [1]-[12]. Previous studies suggest that $20 \%$ to $30 \%$ of patients with VAT may progress to VAP [6] [7] [10]. Bacterial pathogens may enter the lung at the time of intubation, later by leakage around the endotracheal tube cuff, or bacterial biofilm formation and emboli to the lung [2] [5] [6] [9]. Progression from bacterial colonization to VAT or VAP depends on the bacterial virulence, efficacy of pulmonary defenses, such as ciliated epithelium, humoral antibodies, or phagocytosis by polymorphonuclear leukocytes and/or macrophages. [5] [13]

Microbiology criteria used for diagnosing heavy colonization, VAT and VAP include a semi-quantitative tracheal aspirate (SQ-ETA) having $\geq$ moderate $(+++)$ growth of a pathogen which is equivalent to a quantitative tracheal aspirate (Q-ETA) having $\geq 10^{5}$ colony forming units (cfu)/ml [6] [7] [10] [14]. Bronchoscopic or nonbronchoscopic protected specimen brush (PSB) or bronchoaveolar lavage (BAL) samples can also be used to differentiate VAT from VAP [1] [2] [5] [13] [15] [16].

Currently there is no single, accepted "gold standard" for microbiologic or clinical diagnosis of VAT or VAP [1] [4] [9] [15]-[17]. VAT and VAP share similar clinical and microbiologic criteria, but VAP also requires a new and persistent infiltrate on chest X-ray or computer tomographic scan. However, chest X-rays used to diagnose VAP may lack sensitivity or specificity of lung infiltrates that can represent atelectasis, pulmonary emboli, congestive heart failure or adult respiratory distress syndrome or VAP. [18]

Limited data are available on the natural history, incidence, etiology, outcomes and antibiotics treatment of patients with ventilated-associated respiratory infections [5] [6] [14] [19] [20]. This observational study focuses on the natural history of the ventilated patients in ICUs, incidence of heavy tracheal colonization, respiratory infections, pathogens isolated, outcomes and antibiotics use in patients diagnosed with VAT.

\section{Materials and Methods}

\subsection{Study Population and Data Collection}

Details of the study population and inclusion/exclusion criteria were described in previous publication [6]. In this study, 234 ventilated patients in ICUs with SQ-ETA results were included in the data analysis. The day one of study period was defined as enrollment day after ventilation for $\geq 48$ hours. End of study day was the day when patients were extubated, changed to tracheostomy, died or made to comfort measure only. Our research protocol was approved by the Lahey Clinic Institutional Review Board and informed consent process was waived for assessing routine ETA cultures.

\subsection{Microbiologic Methods}

Study samples from routine endotracheal suctioning were collected daily, coded and sent to the microbiology lab for Gram stain and bacterial culture for research purposes only. Gram stains were examined by microscope for the presence of moderate to many polymorphonuclear leukocytes per low power field and several bacteria per high power field using a scale from 0 to many $(++++)$ for both.

SQ-ETA cultures having $\geq$ moderate (+++) growth of a pathogen was considered heavy colonization [4] [6]. Bacterial pathogens were identified by genus and species, using (Microscan ${ }^{\circledR}$, Siemens, Sacramento, CA). Antibiotic sensitivities were performed by the Kirby-Bauer method. 


\subsection{Diagnosis of VAT and VAP}

The diagnosis of VAT and VAP required heavy tracheal colonization, plus at least 2 of 3 clinical signs of infection: temperature $\geq 38^{\circ} \mathrm{C}$ or $\leq 36^{\circ} \mathrm{C}$, leukocytosis $\geq 12,000 / \mathrm{mm}^{3}$ or purulent sputum. Purulent sputum was defined as a Gram-stain with moderate $(+++)$ or many $(++++)$ bacteria/high power microscopic field and moderate $(+++)$ or many $(+++)$ polymorphonuclear leukocytes (PMNL). VAP diagnosis the above clinical and microbiology criteria plus radiologic evidence of a new infiltrate on chest $\mathrm{X}$-ray. Chest $\mathrm{X}$-rays read and reported by a radiologist, were evaluated independently for the presence of new or increasing infiltrate consistent with pneumonia by one of the authors (AS) and compared with the official radiology report. In case of disagreement, three investigators (AS, JH, DC) reviewed films independently and decided on the final reading.

\subsection{Antibiotics Treatment of VAT}

The antibiotics use of the study patients was ordered at the discretion of treating physicians. The reasons for antibiotic administration differed and were as follow: prophylaxis in surgical patients and treatment of various infections including respiratory infections in all patients. The pathogen identification of the daily ETA study specimens was not reported to the treating physicians. The data on antibiotic use were reviewed retrospectively. Analysis of antibiotic administration was performed with focus on the patients with diagnosis of VAT and VAP and within the study period. Antibiotic treatment was considered as appropriate if patient was treated with correct class of antibiotics based on pathogen isolated and susceptibility tests, and whether treatment was initiated within 24 hours of VAT diagnosis.

\subsection{Statistical Analysis}

All comparisons of characteristics between different patient subgroups were unpaired and all tests of significance were two-tailed. Continuous variables were compared using the Student's t-test for normally distributed variables and the Wilcoxon rank-sum test for non-normally distributed variables. The Chi-square or Fisher exact tests were used to compare categorical variables. For all analyses, $p \leq 0.05$ (two-tailed) was considered statistically significant. The statistical analysis for this paper was generated using Statistical Analysis Software (SAS), Version 9.2 for Windows.

\section{Results}

\subsection{Incidence and Outcomes of VAT and VAP}

We studied 234 consecutive medical and surgical patients ventilated $\geq 48$ hours (Figure 1), of which 100 patients (43\%) had a SQ-ETA with $\geq$ moderate $(+++)$ growth of a pathogen on bacterial culture. There were 39 patients (17\%) who only had heavy tracheal colonization, 34 patients (15\%) developed VAT and 34 patients (15\%) developed VAP. Seven of the 34 VAT patients later progressed to VAP in 1 to 7 days or averaged 3 days. Figure 2 demonstrates cumulative incidence rates for patients developing heavy colonization only, VAT and VAP by study day. The rates of heavy colonization, VAT and VAP increased rapidly from study day 1 to study day 10 , and then leveled off.

Baseline variables for the 34 patients diagnosed with VAT, when compared to the 200 patients without VAT (Table 1), demonstrated significant higher CPIS scores $(p<0.0001)$ at study entry and average CPIS scores and fewer patients treated with antibiotics at study entry $(p<0.01)$.

As shown in Figure 1, the outcomes for the 39 patients who had heavy colonization only were not significantly different from the 134 patients with insignificant endotracheal colonization. By comparison, outcomes of the 34 patients diagnosed with VAT when compared to the 200 patient with no VAT demonstrated significantly increased ventilator days (9 vs $6, p<0.001$ ), ICU days (17 vs $11, p<0.001)$ and hospital days (22 vs $17, p<$ 0.001 ) (Figure 1). Patients diagnosed with VAP versus no VAP also had significantly more ventilator days (10.5 vs $6, p<0.001)$ and ICU days (18 vs $11, p<0.001$ ). No significant difference was noted in mortality rates for patients diagnosed with VAT versus no VAT $(18 \%$ vs $29 \%, p=0.24)$ or for patients with VAP versus no $\operatorname{VAP}(27 \%$ vs $28 \%, p=0.90)$.

\subsection{Bacterial Pathogens Identified}

The spectrum of bacterial pathogens isolated from the 34 patients with VAT, which included 27 patients that did 


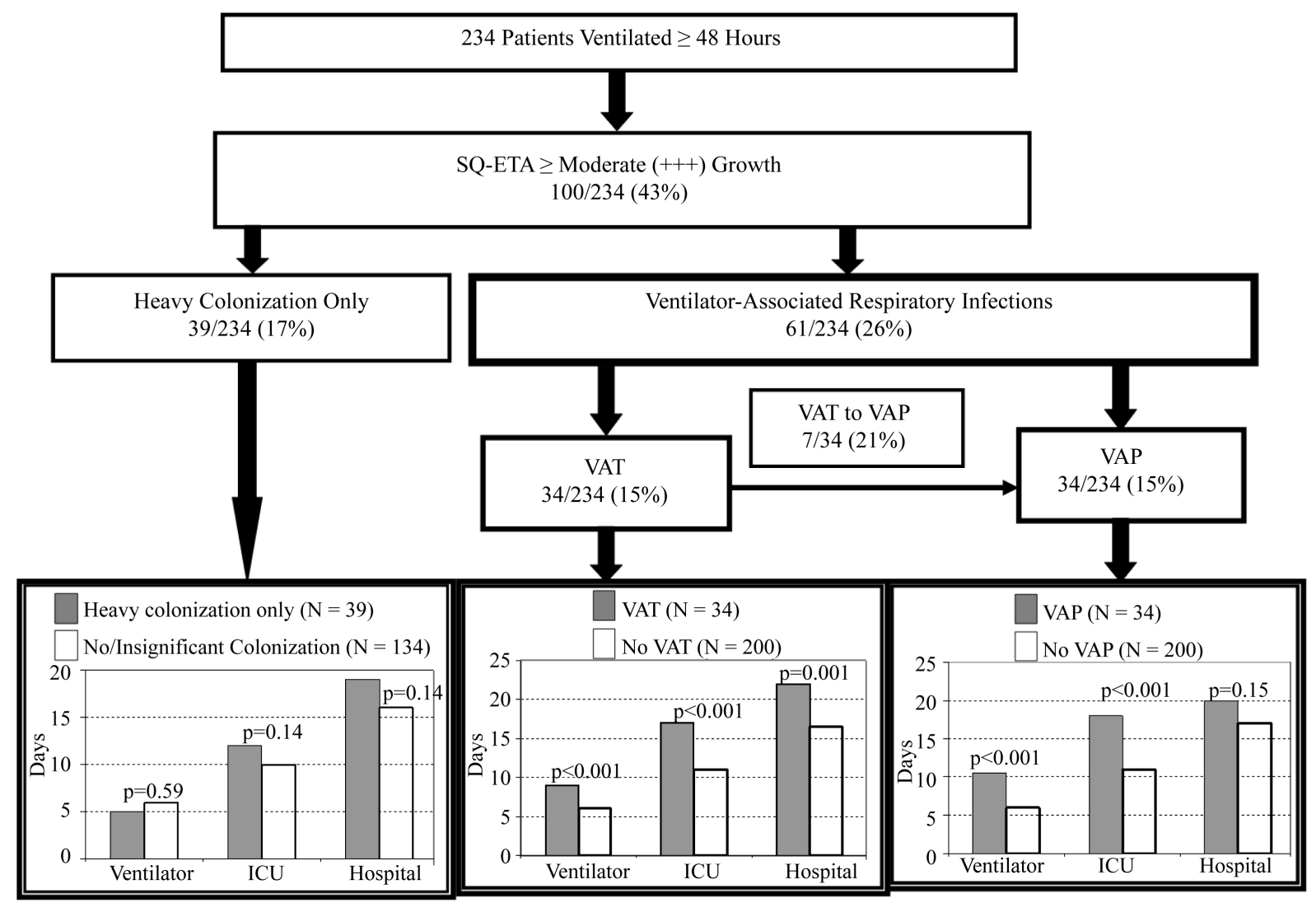

Figure 1. Of the 234 study patients ventilated > 48 hours, 39 (43\%) had heavy colonization only, 34 patients (15\%) developed ventilator-associated tracheobronchitis (VAT) and 34 (15\%) were diagnosed with ventilator-associated pneumonia (VAP). Note that 7 patients diagnosed with VAT later progressed to VAP. Patients diagnosed with VAT or VAP experienced significantly more ventilator days $(p<0.001)$ and longer length of stay in the intensive care unit (ICU) $(p<0.001)$, when compared to patients without VAT or VAP.

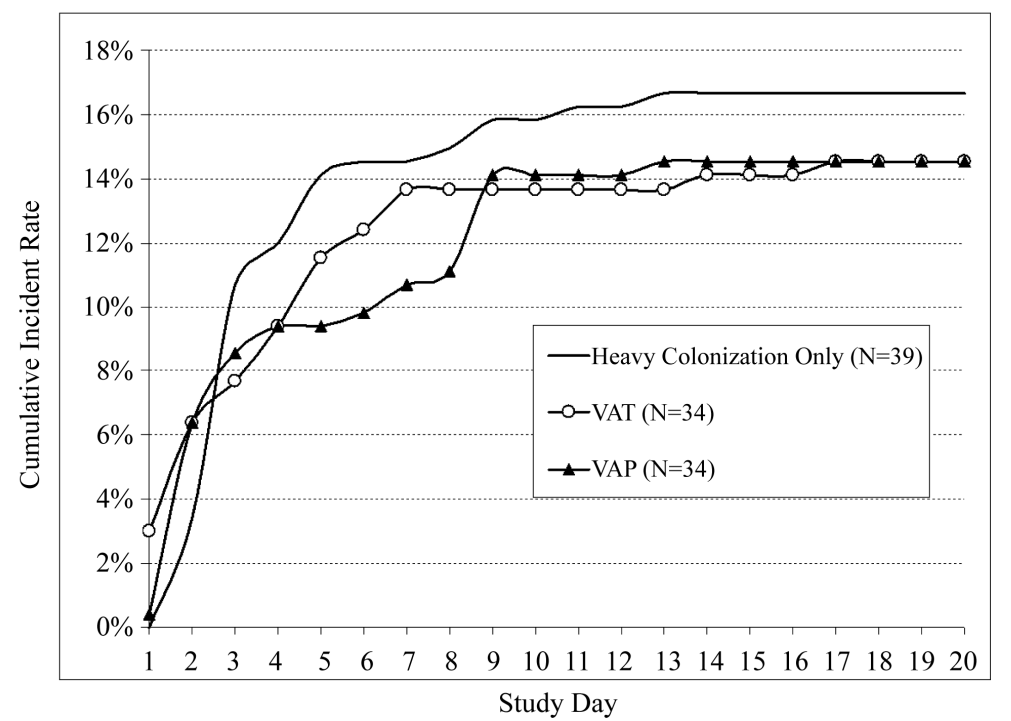

Figure 2. Cumulative incident rates of patients developing heavy colonization, ventilator-associated tracheobronchitis (VAT) and pneumonia (VAP) over time using Kaplan-Meier curves. Note that incident rates increased rapidly during the first ten study days and then leveled off. 
Table 1. Comparision of baseline variables for patients developing ventilator-associated tracheobronchitis (VAT) versus no VAT.

\begin{tabular}{|c|c|c|c|}
\hline Baseline Variables & $\begin{array}{l}\text { VAT } \\
\mathrm{N}=34\end{array}$ & $\begin{array}{l}\text { No VAT } \\
N=200\end{array}$ & $p$ value \\
\hline Age (years) & $62.1 \pm 13.6$ & $65.7 \pm 13.6$ & 0.16 \\
\hline Male & $73.5 \%$ & $60.5 \%$ & 0.15 \\
\hline Body Mass Index & $33.0 \pm 13.0$ & $29.9 \pm 9.4$ & 0.12 \\
\hline Charlson Comorbidity & $1.7 \pm 1.9$ & $2.3 \pm 2.1$ & 0.10 \\
\hline APACHE II $^{\mathrm{a}}$ & $18.1 \pm 6.9$ & $17.6 \pm 5.7$ & 0.74 \\
\hline CPIS $^{\mathrm{b}}$ at Study Entry & $5(2-8)$ & $4(1-8)$ & 0.0001 \\
\hline Average CPIS ${ }^{c}$ & $5(4-8)$ & $4(1-8)$ & $<0.0001$ \\
\hline CPIS $^{d}$ at Diagnosis Day & $6(4-10)$ & - & - \\
\hline Antibiotics at Study Entry & $73.5 \%$ & $89.5 \%$ & 0.01 \\
\hline $\begin{aligned} \operatorname{MICU}^{\mathrm{e}}(\mathbf{N} & =153) \\
\operatorname{SICU}^{\mathrm{f}}(\mathbf{N} & =\mathbf{8 1})\end{aligned}$ & $\begin{array}{l}13.1 \%(20) \\
17.3 \%(14)\end{array}$ & $\begin{array}{c}86.9 \%(133) \\
82.7 \%(67)\end{array}$ & 0.38 \\
\hline
\end{tabular}

${ }^{\mathrm{a}}$ Acute Physiology and Chronic Health Evaluation II; ${ }^{\mathrm{b} C l i n i c a l ~ P u l m o n a r y ~ I n f e c t i o n ~ S c o r e ~ a t ~ s t u d y ~ e n t r y ~ d a y ~} 1$; ${ }^{\mathrm{c}} \mathrm{Clinical}$ Pulmonary Infection Score averaged during whole study days; ${ }^{\mathrm{d}}$ Clinical Pulmonary Infection Score at VAT diagnosis day; ${ }^{\mathrm{e}}$ MICU-Medical intensive care unit; ${ }^{\mathrm{f}}$ SICU-Surgical intensive care unit.

not progress to VAP and the 7 VAT patients that progressed to VAP are shown in Table 2. Staphylococcus aureus was isolated in 19/34 patients (56\%) of the patients diagnosed with VAT, of which 13/19 (67\%) were methicilllin-resistant S. aureus (MRSA) and 6/19 (33\%) were methicilllin-sensitive S. aureus (MSSA) that likely reflects increased virulence of $S$. aureus isolates compared to the other pathogens isolated [21] [22]. Five of the 7 (71\%) patients that progressed from VAT to VAP were infected with S. aureus (4 MSSA and 1 MRSA). Klebsiella pneumoniae and Pseudomonas aeruginosa were most common Gram-negative pathogens isolated. Seventy-nine percent of VAT patients had one pathogen infection, 12\% had two pathogens and 9\% had three pathogens.

As shown in Figure 3, the patient was diagnosed with ventilator associated tracheobronchitis (VAT) on day 2, caused by many $(++++)$ growth of Serratia marcescens (solid circles). Timely and appropriate cefepime was started for VAT caused by Serratia marcescens on days 1 to 8 . On day 4, however, there was moderate (+++) growth of Stenotrophomonas maltophilia (open squares). No antibiotics were received for S. maltophilia until day 6, when appropriate trimethoprim/sulfamethoxazole (TMP-SMX) was prescribed up to day 12. On day 8, there was few (+++) growth of Pseudomonas aeruginosa (open triangles). Inappropriate therapy with cefepime resistance based on susceptibility testing) was given for $P$. aeruginosa until day 11 . At the end of study period on day 12, appropriate therapy with amikacin was received for $P$. aeruginosa. The patient developed ventilator-associated pneumonia (VAP) on day 9 with moderate (+++) growth of S. maltophilia and P. aeruginosa.

Of the 34 VAT patients studied, 25 who received appropriate intravenous antibiotics within 24 hours were compared to 9 patients who did not receive timely appropriate antibiotics (Table 3). The two groups had similar characteristics such as age, sex, body mass index, co-morbidity, Acute Physiology and Chronic Health Evaluation II (APACHE II) score and Clinical Pulmonary Infection Score (CPIS) at VAT diagnosis. As shown in Table 4 , no significant differences were observed in VAP rate (20\% vs $22 \%, p=1.0)$, ventilator days (11 vs 10 days, $p=0.9$ ), ICU days (20 vs $15, p=0.1$ ), hospital days (25 vs $19, p=0.3$ ), or hospital mortality ( $24 \%$ vs $22 \%$, $p=1)$.

\section{Discussion}

The incident rate of VAT was 15\%, of which $21 \%$ later progressed to VAP. Patients developing VAT had significantly increased ventilator, ICU and hospital days which have been observed by others [23]. Seventy-four percent of VAT patients received timely and appropriate antibiotic treatment for VAT. Antibiotic treatment can 
Table 2. Pathogens isolated from the 34 patients with ventilator-associated tracheobronchitis (VAT). The VAT patients were grouped into 27 patients that did not progress to VAP versus the 7 patients that progressed to VAP.

\begin{tabular}{|c|c|c|c|}
\hline Pathogens & $\begin{array}{l}\text { All VAT patients } \\
\quad(\mathrm{N}=34)\end{array}$ & $\begin{array}{l}\text { VAT did not progressed } \\
\text { to VAP }(\mathrm{N}=27)\end{array}$ & $\begin{array}{l}\text { VAT progressed to VAP } \\
\qquad(\mathrm{N}=7)\end{array}$ \\
\hline $\begin{array}{l}\text { Gram-Positive Cocci } \\
\text { Methicillin-resistant Staphylococcus aureus }\end{array}$ & $13(38 \%)$ & $12(44 \%)$ & $1(14 \%)$ \\
\hline Methicillin-sensitive Staphylococcus aureus & $6(18 \%)$ & $2(7 \%)$ & $4(57 \%)$ \\
\hline Enterococcus species & $2(6 \%)$ & $2(7 \%)$ & 0 \\
\hline $\begin{array}{l}\text { Gram-Negative Pathogens } \\
\text { Psudomonas aeruginosa }\end{array}$ & $3(9 \%)$ & $2(7 \%)$ & $1(14 \%)$ \\
\hline Escherichia coli & $2(6 \%)$ & $1(4 \%)$ & $1(14 \%)$ \\
\hline Klebsiella pneumoniae & $5(15 \%)$ & $4(15 \%)$ & $1(14 \%)$ \\
\hline Klebsiella oxytoca & $1(3 \%)$ & 0 & $1(14 \%)$ \\
\hline Enterobacter species & $1(3 \%)$ & $1(4 \%)$ & 0 \\
\hline Serratia marcescens & $2(6 \%)$ & $2(7 \%)$ & 0 \\
\hline Proteus mirabilis & $1(3 \%)$ & $1(4 \%)$ & 0 \\
\hline Stenotrophomonas maltophilia & $2(6 \%)$ & $1(4 \%)$ & $1(14 \%)$ \\
\hline Acinectobacter baumannii & $1(3 \%)$ & $1(4 \%)$ & 0 \\
\hline Chryseobacterium species & $1(3 \%)$ & $1(4 \%)$ & 0 \\
\hline Haemophilus influenza & $2(6 \%)$ & $1(4 \%)$ & $1(14 \%)$ \\
\hline One Pathogen & 27 (79\%) & $23(86 \%)$ & $4(57 \%)$ \\
\hline Two Pathogens & $4(12 \%)$ & $2(7 \%)$ & $2(29 \%)$ \\
\hline Three Pathogens & $3(9 \%)$ & $2(7 \%)$ & $1(14 \%)$ \\
\hline
\end{tabular}

Table 3. Baseline variables for the 34 patients with ventilator-associated tracheobronchitis (VAT). Comparison was made between the patients who received appropriate antibiotics within 24 hours of diagnosis and the patients who did not receive appropriate antibiotics.

\begin{tabular}{cccc}
\hline Baseline Variables & $\begin{array}{c}\text { Appropriate } \\
\text { antibiotics (N = 25) }\end{array}$ & $\begin{array}{c}\text { Not appropriate } \\
\text { antibiotics (N = 9) }\end{array}$ & $\boldsymbol{p}$ \\
\hline Age (years) & $61.7 \pm 12.0$ & $65.3 \pm 17.9$ & 0.50 \\
Male, n (\%) & $18(72.0 \%)$ & $7(77.8) \%$ & 0.74 \\
Body Mass Index & $34.5 \pm 14.1$ & $28.6 \pm 7.6$ & 0.31 \\
Charlson Comorbidity & $1.8 \pm 2.1$ & $1.6 \pm 1.1$ & 0.78 \\
APACHE II & $18.4 \pm 7.2$ & $17.3 \pm 6.4$ & 0.70 \\
CPIS $^{\mathbf{b}}$ at VAT Diagnosis & $6(4-10)$ & $5(4-8)$ & 0.20 \\
MICU $^{\mathbf{c}}(\mathbf{n}=\mathbf{1 2})$ & $9 / 12(75.0 \%)$ & $3 / 12(25.0 \%)$ & 0.89 \\
SICU $\left.^{(\mathbf{n}}=\mathbf{2 2}\right)$ & $16 / 22(72.7 \%)$ & $6 / 22(27.3 \%)$ &
\end{tabular}

${ }^{\mathrm{a}}$ Acute Physiology and Chronic Health Evaluation II; ${ }^{\mathrm{b}}$ Clinical Pulmonary Infection Score; ${ }^{\mathrm{c}}$ MICU—Medical intensive care unit; ${ }^{\mathrm{d}}$ SICU—Surgical intensive care unit.

be complicated in patients with multiple, new or MDR pathogens, as shown in Figure 3. The predominant pathogens isolated in our study were $S$. aureus, $P$. aeruginosa and K. pneumoniae, all of which have increased virulence for lung tissue and higher mortality [21] [24]-[28].

Our analysis of 34 VAT patients with or without timely appropriate antibiotics treatment did not show statis- 


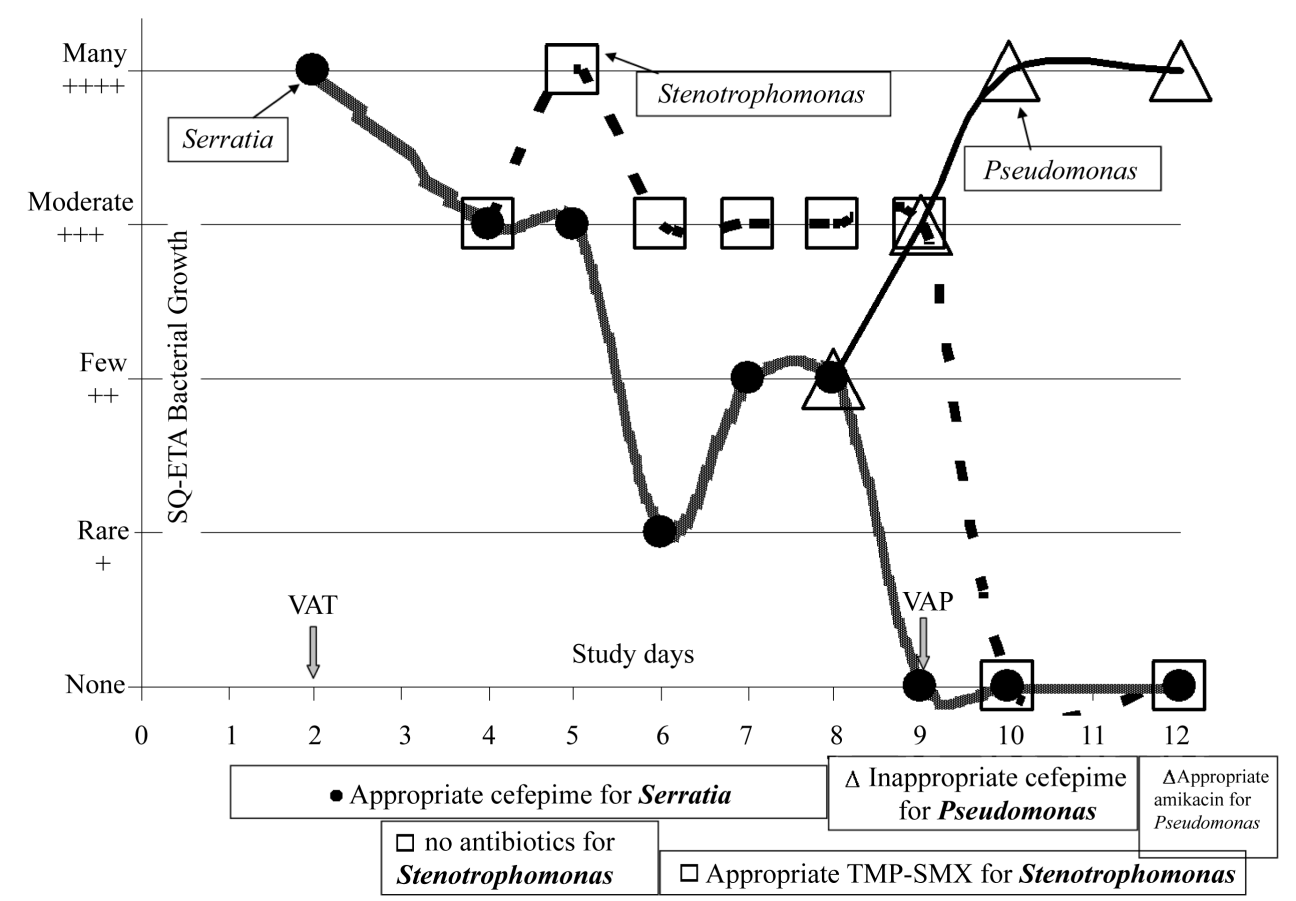

Figure 3. The patient was diagnosed with ventilator associated tracheobronchitis (VAT) on day 2, caused by many (++++) growth of Serratia marcescens (solid circles). Timely and appropriate cefepime was received for Serratia on day 1 to 8. On day 4, there was moderate $(+++)$ growth of Stenotrophomonas maltophilia (open squares). No antibiotics were received for Stenotrophomonas until day 6, when appropriate Trimethoprim/sulfamethoxazole (TMP-SMX) was used till day 12. On day 8, there was few (+++) growth of Pseudomonas aeruginosa (open triangles). Inappropriate cefepime was received for until day 11. At the end of study period on day 12, appropriate amikacin was received for Pseudomonas. The patient developed ventilator-associated pneumonia (VAP) on day 9 with moderate $(+++)$ growth of Stenotrophomonas and Pseudomon.

Table 4. Outcomes of the patients treated with appropriate antibiotics within 24 hours of ventilator-associated thacheobronchitis. VAT diagnosis versus the patients who did not received timely appropriate antibiotics.

\begin{tabular}{cccc}
\hline Outcomes & $\begin{array}{c}\text { Appropriate } \\
\text { antibiotics } \\
\mathbf{N}=\mathbf{2 5}\end{array}$ & $\begin{array}{c}\text { Not appropriate } \\
\text { antibiotics } \\
\mathbf{N}=\mathbf{9}\end{array}$ & $\boldsymbol{p}$ Value \\
\hline VAP $^{\mathbf{a}}$ Rate & $5 / 25(20.0 \%)$ & $2 / 9(22.2 \%)$ & 1.00 \\
Ventilator Days (min-max) & $11(4-22)$ & $10(6-18)$ & 0.91 \\
ICU Days (min-max) & $20(6-56)$ & $15(10-31)$ & 0.14 \\
Hospital Days (min-max) & $25(7-107)$ & $19(11-51)$ & 0.30 \\
Mortality & $6 / 25(24.0 \%)$ & $2 / 9(22.2 \%)$ & 1.00 \\
\hline
\end{tabular}

${ }^{\mathrm{a}}$ Ventilator-associated pneumonia; ${ }^{\mathrm{b}}$ Intensive care unit.

tically significant differences in VAP rate, ventilator days, ICU days and hospital stay (Table 4). Of note is that our study was a natural history study used daily assessment of tracheobronchial colonization, which was not reported back to treating physicians. Thus, the use of antibiotics was at the discretion of treating physicians. As shown in Figure 3, it might have been helpful to order timely and appropriate use of antibiotics, if the daily SQ-ETA results were available for treating physicians.

The finding that appropriate antibiotics treatment for VAT did not improve outcomes was disappointing. It is important to emphasize that this was a natural history study and clinicians treated patients at their discretion based on microbiological data they ordered, as they were blinded to surveillance cultures. Antibiotic administra- 
tion that included prophylaxis as well as therapeutic coverage for other infections occurred throughout the course of the ICU stay. Many patients were treated with numerous antibiotics for other reasons from one day to 2 weeks. Although we evaluated appropriateness and timing of antibiotics referenced to the diagnosis of VAT, it was often impossible to map antibiotic treatment throughout the ICU stay, due to erratic patterns.

Several studies have supported treatment of VAT to prevent VAP and improve patient outcomes, but this is not a current "standard of care" [3] [5] [10] [13] [14] [29] [30]. A controlled and unblinded, multicenter clinical trial assessed the impact of antibiotic therapy for VAT for 22 study patients randomized to "early" antibiotic therapy versus 36 patients given "delayed" therapy" [20]. Early antibiotic therapy for VAT significantly decreased progression to VAP ( $13 \%$ vs $47 \%, p<0.05)$, increased "ventilator free" days (22 vs $36, p<0.001$ ) and decreased patient mortality (18\% vs $47 \%, p<0.05)$. [20] A more recent prospective observational study by Nseir et al demonstrated that appropriate antibiotic treatment was independently associated with reduced risk of transition from VAT to VAP [31]. There were 17 of 122 VAT patients (14\%) that progressed to VAP, of which 58 (48\%) received appropriate antibiotic treatment, which was the only factor independently associated with reduced transition from VAT to VAP $(p=0.009)$. Our data showed that $21 \%$ of the VAT patients later developed VAP, which was higher than the 14\% reported by Nseir and coworkers [31]. There is increasing interest in using intravenous $+/-$ aerosolized antibiotics delivered by improved nebulizers, placed in the ventilators circuit, to treat more virulent or drug-resistant pathogen(s), such as S. aureus, P. aeruginosa, K. pneumoniae or A. baumannii. [21] [24] [26]-[28] [32]. Aerosolized antibiotic therapy can deliver higher doses of antibiotic(s) to lung parenchyma that is not absorbed systemically, and therefore reduces the risk of Clostridium difficile infection.

Our data noted time of progression from VAT to VAP was 1 to 7 days or an average of 3 days. This window allows treating physicians the opportunity to prescribe earlier targeted antibiotics to treat VAT, based on the microbiology results of surveillance cultures (e.g. SQ-ETA) and to follow the host response to treatment. Over the past two years, there has been increased interest in rapid diagnostic methods to identify bacterial pathogens and antibiotic sensitivities in sputum and blood samples, using various techniques, such as MALDI-TOF [33] [34]. These new rapid diagnostic methods may change the current management landscape and facilitate the earlier, appropriate antibiotic treatment for VAT and VAP. We currently have a universal model for treating upper and lower urinary tract infections in patients with pyuria and bacterial culture with $\geq 10^{5} \mathrm{cfu} / \mathrm{ml}$, which bacteria can be easily drained by urinating or bladder catheter [5] [13]. This treatment model could be extrapolated to the optimal management of VAT.

Our natural history study had several limitations. Small sample size was included in the analysis of antibiotics treatment for VAT. High proportion of patients was on antibiotics at study entry and received inconsistent treatment with antibiotics throughout the ICU stay. Controlled trials with pre-determined antibiotic coverage, strict duration of treatment, testing shorter vs. longer courses of therapy, and comparing standard intravenous +/aerosolized therapy are needed. We recommend that future studies should focus on earlier diagnosis of VAT, use of randomized, double blind treatment models with assessment of the risks and benefits of intravenous versus aerosolized antibiotics delivered by improved delivery systems [32].

\section{Conclusion}

In our intensive care units, $15 \%$ of ventilated patients developed VAT. About one fifth of the VAT cases progressed to VAP. VAT was a risk factor for increased ventilator days, longer length of ICU and hospital stay. Staphylococcus aureus was the most common pathogen isolated and had the highest rate of progression from VAT to VAP. Our study showed that about three quarters of patients received timely appropriate antibiotics treatment for VAT. The data collected from the natural course of the antibiotics treatment did not show significant better clinical outcomes for patients who received appropriate antibiotics for VAT. The effectiveness of antibiotics treatment for VAT needed to be carefully assessed with well-designed, larger randomized clinical studies. The time window from VAT to VAP was an average of 3 days, which allowed physicians an opportunity to identify the pathogens, and to treat VAT with targeted appropriate antibiotics in order to prevent VAP, improve patient outcomes and reduce healthcare costs.

\section{Acknowledgements}

The authors thank Joyce Pelletier, CRT, CRA, Sarah Zimmerman, MT and special thanks to the respiratory care team, microbiology team, the medical and surgical ICU nurses for their support and assistance with the study. 
Abstracts of these data were presented at the $49^{\text {th }}$ Infectious Disease Society of America (IDSA), Annual Meeting, Boston, October MA 2011; the American Society of Chest Physicians, Honolulu, Hawaii, October 2011; the Infectious Diseases of America (IDSA) Week, San Francisco, CA, October 5-8, 2013, and IDSA Week Philadelphia, PA in 2014.

\section{Financial Support}

This work was supported by grants from the Wise Foundation, Lahey Clinic (LCID2010-004) and Pfizer Pharmaceuticals (WS480336) to D.E.C.

\section{Conflict of Interests}

No conflict.

\section{References}

[1] ATS Board of Directors and the IDSA Guideline Committee (2005) Guidelines for the Management of Adults with Hospital-Acquired, Ventilator-Associated, and Healthcare-Associated Pneumonia. American Journal of Respiratory and Critical Care Medicine, 171, 388-416. http://dx.doi.org/10.1164/rccm.200405-644ST

[2] Chastre, J. and Fagon, J.Y. (2002) Ventilator-Associated Pneumonia. American Journal of Respiratory and Critical Care Medicine, 165, 867-903. http://dx.doi.org/10.1164/ajrccm.165.7.2105078

[3] Craven, D.E., Chroneou, A., Zias, N. and Hjalmarson, K.I. (2009) Ventilator-Associated Tracheobronchitis: The Impact of Targeted Antibiotic Therapy on Patient Outcomes. Chest, 135, 521-528. http://dx.doi.org/10.1378/chest.08-1617

[4] Craven, D.E., Hudcova, J. and Lei, Y. (2011) Diagnosis of Ventilator-Associated Respiratory Infections (VARI): Microbiologic Clues for Tracheobronchitis (VAT) and Pneumonia (VAP). Clinics in Chest Medicine, 32, 547-357. http://dx.doi.org/10.1016/j.ccm.2011.06.001

[5] Craven, D.E., Hudcova, J. and Rashid, J. (2015) Antibiotic Therapy for Ventilator-Associated Tracheobronchitis: A Standard of Care to Reduce Pneumonia, Morbidity and Costs? Current Opinion in Pulmonary Medicine, 21, 250-259. http://dx.doi.org/10.1097/MCP.0000000000000158

[6] Craven, D.E., Lei, Y., Ruthazer, R., Sarwar, A. and Hudcova, J. (2013) Incidence and Outcomes of Ventilator-Associated Tracheobronchitis and Pneumonia. American Journal of Medicine, 126, 542-549. http://dx.doi.org/10.1016/j.amjmed.2012.12.012

[7] Dallas, J., Skrupky, L., Abebe, N., Boyle, W.A. and Kollef, M.H. (2011) Ventilator-Associated Tracheobronchitis in a Mixed Surgical and Medical ICU Population. Chest, 139, 513-518. http://dx.doi.org/10.1378/chest.10-1336

[8] Karvouniaris, M., Makris, D., Manoulakas, E., Zygoulis, P., Mantzarlis, K., Triantaris, A., Chatzi, M. and Zakynthinos, E. (2013) Ventilator-Associated Tracheobronchitis Increases the Length of Intensive Care Unit Stay. Infection Control \& Hospital Epidemiology, 34, 800-808. http://dx.doi.org/10.1086/671274

[9] Niederman, M.S. (2005) The Clinical Diagnosis of Ventilator-Associated Pneumonia. Respiratory Care, 50, 788-796. http://dx.doi.org/10.1201/b14114-9

[10] Nseir, S., Ader, F. and Marquette, C.H. (2009) Nosocomial Tracheobronchitis. Current Opinion in Infectious Diseases, 22, 148-153. http://dx.doi.org/10.1097/QCO.0b013e3283229fdb

[11] Palmer, L.B. (2009) Ventilator-Associated Infection. Current Opinion in Pulmonary Medicine, 15, $230-235$. http://dx.doi.org/10.1097/MCP.0b013e3283292650

[12] Torres, A. and Carlet, J. (2001) Ventilator-Associated Pneumonia. European Task Force on Ventilator-Associated Pneumonia. European Respiratory Society, 17, 1034-1045. http://dx.doi.org/10.1183/09031936.01.17510340

[13] Craven, D.E., Hudcova, J., Craven, K.A., Scopa, C. and Lei, Y. (2014) Antibiotic Treatment of Ventilator-Associated Tracheobronchitis: To Treat or Not to Treat? Current Opinion in Critical Care, 20, 532-541. http://dx.doi.org/10.1097/MCC.0000000000000130

[14] Nseir, S., Di Pompeo, C., Pronnier, P., Beague, S., Onimus, T., Saulnier, F., Grandbastien, B., Mathieu, D., DelvallezRoussel, M. and Durocher, A. (2002) Nosocomial Tracheobronchitis in Mechanically Ventilated Patients: Incidence, Aetiology and Outcome. European Respiratory Society, 20, 1483-1489. http://dx.doi.org/10.1183/09031936.02.00012902

[15] Fagon, J.Y. (2006) Diagnosis and Treatment of Ventilator-Associated Pneumonia: Fiberoptic Bronchoscopy with Bronchoalveolar Lavage Is Essential. Seminars in Respiratory and Critical Care Medicine, 27, 34-44. 
http://dx.doi.org/10.1055/s-2006-933672

[16] Rea-Neto, A., Youssef, N.C., Tuche, F., Brunkhorst, F., Ranieri, V.M., Reinhart, K. and Sakr, Y. (2008) Diagnosis of Ventilator-Associated Pneumonia: A Systematic Review of the Literature. Critical Care, 12, R56. http://dx.doi.org/10.1186/cc6877

[17] Shorr, A.F., Sherner, J.H., Jackson, W.L. and Kollef, M.H. (2005) Invasive Approaches to the Diagnosis of Ventilator-Associated Pneumonia: A Meta-Analysis. Critical Care Medicine, 33, 46-53. http://dx.doi.org/10.1097/01.CCM.0000149852.32599.31

[18] Wunderink, R.G. (2000) Radiologic Diagnosis of Ventilator-Associated Pneumonia. Chest, 117, 188S-190S. http://dx.doi.org/10.1378/chest.117.4_suppl_2.188S

[19] Nseir, S., Di Pompeo, C., Soubrier, S., Delour, P., Onimus, T., Saulnier, F. and Durocher, A. (2004) Outcomes of Ventilated COPD Patients with Nosocomial Tracheobronchitis: A Case-Control Study. Infection, 32, 210-216. http://dx.doi.org/10.1007/s15010-004-3167-0

[20] Nseir, S., Favory, R., Jozefowicz, E., Decamps, F., Dewavrin, F., Brunin, G., Di Pompeo, C., Mathieu, D. and Durocher, A. (2008) Antimicrobial Treatment for Ventilator-Associated Tracheobronchitis: A Randomized, Controlled, Multicenter Study. Critical Care, 12, R62. http://dx.doi.org/10.1186/cc6890

[21] Lowy, F.D. (1998) Staphylococcus aureus Infections. The New England Journal of Medicine, 339, 520-532. http://dx.doi.org/10.1056/NEJM199808203390806

[22] Stulik, L., Malafa, S., Hudcova, J., Rouha, H., Henics, B.Z., Craven, D.E., Sonnevend, A.M. and Nagy, E. (2014) Alpha-Hemolysin Activity of Methicillin-Susceptible Staphylococcus aureus Predicts Ventilator-Associated Pneumonia. American Journal of Respiratory and Critical Care Medicine, 190, 1139-1148. http://dx.doi.org/10.1164/rccm.201406-1012OC

[23] Nseir, S., Di Pompeo, C., Soubrier, S., Lenci, H., Delour, P., Onimus, T., Saulnier, F., Mathieu, D. and Durocher, A. (2005) Effect of Ventilator-Associated Tracheobronchitis on Outcome in Patients without Chronic Respiratory Failure: A Case-Control Study. Critical Care, 9, R238. http://dx.doi.org/10.1186/cc3508

[24] Crouch Brewer, S., Wunderink, R.G., Jones, C.B. and Leeper Jr., K.V. (1996) Ventilator-Associated Pneumonia Due to Pseudomonas aeruginosa. Chest, 109, 1019-1029. http://dx.doi.org/10.1378/chest.109.4.1019

[25] Nseir, S., Deplanque, X., Di Pompeo, C., Diarra, M., Roussel-Delvallez, M. and Durocher, A. (2008) Risk Factors for Relapse of Ventilator-Associated Pneumonia Related to Nonfermenting Gram Negative Bacilli: A Case-Control Study. Journal of Infection, 56, 319-325. http://dx.doi.org/10.1016/j.jinf.2008.02.012

[26] Planquette, B., Timsit, J.F., Misset, B.Y., Schwebel, C., Azoulay, E., Adrie, C., Vesin, A., Jamali, S., Zahar, J.R., Allaouchiche, B., Souweine, B., Darmon, M., Dumenil, A.S., Goldgran-Toledano, D., Mourvillier, B.H. and Bedos, J.P. (2013) Pseudomonas aeruginosa ventilator-associated pneumonia. Predictive factors of Treatment Failure. American Journal of Respiratory and Critical Care Medicine, 188, 69-76. http://dx.doi.org/10.1164/rccm.201210-1897OC

[27] Sawa, T. (2014) The Molecular Mechanism of Acute Lung Injury Caused by Pseudomonas aeruginosa: From Bacterial Pathogenesis to Host Response. Journal of Intensive Care, 2, 10. http://dx.doi.org/10.1186/2052-0492-2-10

[28] Van Delden, C. and Iglewski, B.H. (1998) Cell-to-Cell Signaling and Pseudomonas aeruginosa Infections. Emerging Infectious Diseases, 4, 551-560. http://dx.doi.org/10.3201/eid0404.980405

[29] Agrafiotis, M., Siempos, I.I. and Falagas, M.E. (2010) Frequency, Prevention, Outcome and Treatment of Ventilator-Associated Tracheobronchitis: Systematic Review and Meta-Analysis. Respiratory Medicine, 104, 325-336. http://dx.doi.org/10.1016/j.rmed.2009.09.001

[30] Palmer, L.B., Smaldone, G.C., Chen, J.J., Baram, D., Duan, T., Monteforte, M., Varela, M., Tempone, A.K., O’Riordan, T., Daroowalla, F. and Richman, P. (2008) Aerosolized Antibiotics and Ventilator-Associated Tracheobronchitis in the Intensive Care Unit. Critical Care Medicine, 36, 2008-2013. http://dx.doi.org/10.1097/CCM.0b013e31817c0f9e

[31] Nseir, S., Martin-Loeches, I., Makris, D., Jaillette, E., Karvouniaris, M., Valles, J., Zakynthinos, E. and Artigas, A. (2014) Impact of Appropriate Antimicrobial Treatment on Transition from Ventilator-Associated Tracheobronchitis to Ventilator-Associated Pneumonia. Critical Care, 18, R129. http://dx.doi.org/10.1186/cc13940

[32] Montgomery, A.B., Vallance, S., Abuan, T., Tservistas, M. and Davies, A. (2014) A Randomized Double-Blind Placebo-Controlled Dose-Escalation Phase 1 Study of Aerosolized Amikacin and Fosfomycin Delivered via the PARI Investigational eFlow Inline Nebulizer System in Mechanically Ventilated Patients. Journal of Aerosol Medicine and Pulmonary Drug Delivery, 27, 441-448.

[33] Burnham, C.A., Frobel, R.A., Herrera, M.L. and Wickes, B.L. (2014) Rapid Ertapenem Susceptibility Testing and Klebsiella pneumoniae Carbapenemase Phenotype Detection in Klebsiella pneumoniae Isolates by Use of Automated Microscopy of Immobilized Live Bacterial Cells. Journal of Clinical Microbiology, 52, 982-986. http://dx.doi.org/10.1128/JCM.03255-13 
[34] Laffler, T.G., Cummins, L.L., McClain, C.M., Quinn, C.D., Toro, M.A., Carolan, H.E., Toleno, D.M., Rounds, M.A., Eshoo, M.W., Stratton, C.W., Sampath, R., Blyn, L.B., Ecker, D.J. and Tang, Y.W. (2013) Enhanced Diagnostic Yields of Bacteremia and Candidemia in Blood Specimens by PCR-Electrospray Ionization Mass Spectrometry. Journal of Clinical Microbiology, 51, 3535-3541. http://dx.doi.org/10.1128/JCM.00876-13 